\title{
Using Multivariable Linear Regression Technique for Modeling Productivity Construction in Iraq
}

\author{
Faiq Mohammed Sarhan Al-Zwainy ${ }^{1}$, Mohammed Hashim Abdulmajeed ${ }^{2}$, \\ Hadi Salih Mijwel Aljumaily ${ }^{3}$ \\ ${ }^{1}$ Department of Civil Engineering, College of Engineering, Al-Nahrain University, Baghdad, Iraq \\ ${ }^{2}$ Ministry Industry and Minerals, State Industrial Design and Consultation Company (Sidcco), Baghdad, Iraq \\ ${ }^{3}$ Department of Environmental Engineering, College of Engineering, Al-Mustansiriya University, Baghdad, Iraq \\ Email: FAIQ_FAIQMOHMED@yahoo.com
}

Received June 2, 2013; revised July 2, 2013; accepted July 9, 2013

Copyright (C) 2013 Faiq Mohammed Sarhan Al-Zwainy et al. This is an open access article distributed under the Creative Commons Attribution License, which permits unrestricted use, distribution, and reproduction in any medium, provided the original work is properly cited.

\begin{abstract}
Productivity is a very important element in the process of construction project management especially with regard to the estimation of the duration of the construction activities, this study aims at developing construction productivity estimating model for marble finishing works of floors using Multivariable Linear Regression technique (MLR). The model was developed based on 100 set of data collected in Iraq for different types of projects such as residential, commercial and educational projects. Which these are used in developing the model and evaluating its performance. Ten influencing factors are utilized for productivity forecasting by MLR model, and they include age, experience, number of the assist labor, height of the floor, size of the marbles tiles, security conditions, health status for the work team, weather conditions, site condition, and availability of construction materials. One model was built for the prediction of the productivity of marble finishing works for floors. It was found that MLR have the ability to predict the productivity for finishing works with excellent degree of accuracy of the coefficient of correlation $(R) 90.6 \%$, and average accuracy percentage of $96.3 \%$. This indicates that the relationship between the independent and independent variables of the developed models is good and the predicted values from a forecast model fit with the real-life data.
\end{abstract}

Keywords: Multivariable Linear Regression Techniques; Construction Productivity; Finishing Work; Coefficient of Correlation

\section{Introduction}

Productivity rates of construction trades are the basis for accurately estimating time and costs required to complete a project. Productivity could be defined as "the ratio of output of required quality to the inputs" for a specific production situation; in the construction industry, it is generally accepted as "work output per man-hours worked". Improved productivity helps contractors not only to be more efficient and profitable; knowing actual productivity levels also helps them to estimate accurately and be more competitive during bidding for projects.

In response to the industry needs, the primary goal of this research was to conduct an accurate measurement of on-site construction productivity in Iraq through developing regression models for predicting the productivity of finishing works for floors with marble. The structure of research is consisting of Research justifications, Research hypothesis, Research methodology, Literature re- view, Factors affecting construction productivity, field data collection, regression models for productivity, validation of models, Conclusion, recommendations and future research.

It is widely accepted that productivity measurement plays an important role in the construction management process. Productivity measurement provides the necessary data to analyze factors for project owners, constructors, and management professionals to control construction progress, estimate the cost of future construction projects, and determine its competitiveness in the global market. In achieving these objectives, the researcher hoped that it could help the Iraq construction firms stay competitive and profitable in the global markets.

\section{Research Justifications}

The reasons that stand behind the adoption of this study work are: 
1) There are different techniques currently used for construction productivity estimation at different stages of the project development process. Some of these methods suffer the major disadvantages of lack of precision, aged, slow and uncertainty.

2) Construction sector in Iraq needing for modern efficient construction productivity estimation techniques that have more advantages such as, being modern, fast, accurate, flexible and easy to use is of value.

\section{The Research Hypothesis}

The research hypothesis is formulated as "Multivariable Linear Regression (MLR) has strong modeling technique with optimization mechanism and effective recognition capabilities to estimate the production rates under any specific condition".

\section{Research Methodology}

The research objectives were achieved by using the following steps:

1) Literature review: A comprehensive literature review was conducted to provide the previous research studies related to the construction productivity and to understand the current Iraq construction industry. The review synthesized the findings from previous literature in textbooks, journal papers, research reports, conference proceedings, theses, dissertations, and Internet publications, and methods of productivity data analyses. The review enabled the researcher to better understand the current status of the field research and to perform studies in both accuracy and practicability;

2) Data collection: The researcher conducted on-site construction productivity measurements in the Iraq. The data were collected from observation and recompiled to a spreadsheet format that is suitable for statistical data analysis by using computer software, such as Statistical Package for the Social Sciences (SPSS);

3) Data analysis and comparison: The data analysis were conducted by using the statistical software package, SPSS 19.0, for determining the productivity rate characteristics, and labor productivity. Various statistical analysis methods, including descriptive statistics, correlation, and nonparametric tests, were also used for modeling throughout the research;

4) Developed Model: Based on the data analyses' results, it will provide Multiple Linear Regression model to predicting productivity of marble finishing works for floors and discuses the results from training and testing this model;

5) Validation Model: This stage, which presented the validation of the MLR model;

6) Conclusions, recommendations and future research: Based on the results of the data analyses developed model and validation model, conclusions and recommendations were provided for this research. The conclusions included the characteristics of the labor productivity, production effectiveness. In addition, corrective actions and future research were recommended for other researchers who are interested in further research on this topic.

\section{Available Productivity Estimation Techniques}

Labor productivity estimates are often performed by individuals using combinations of analytical techniques and personal judgment [1]; namely, the worker hour estimates are usually obtained through direct interaction with a scheduler, the site manager or related sub-contractors who are knowledgeable enough to reflect the actual conditions of a project and its constituent activities [2]. These individuals often have a library of basic productivity rates which are adjusted and recalculated for each project [3], and always modify their productivity rates for each specific estimate [4]. On the other hand, differences in these productivity rates are always likely and normal [5].

A number of techniques for motion and time study such as time-lapse photography and video can be used along with statistics for analyzing and estimating construction-operation productivity [6]. Mathematical models and discrete event simulation techniques can also be applied. This paper presents an alternative approach that utilizes the adaptively of multivariable linear regression to perform the complex mapping from environment and management conditions to operation productivity.

One of the most importance techniques is statisticbased called the multivariable linear regression. It attempts to map the relationships between the influential factors and the productivity with the explicit mathematical functions. The mapping functions are initially presumed and later evaluated. They could be linear functions (multivariable linear regression) or non-linear functions (multivariable non-linear regression). However, the statistical technique could oversimplify the relationships comparing with the neural network technique [7].

\section{Previous Studies on the Construction Productivity}

Extensive research has been undertaken in construction labor productivity in the past 35 years. These research works can be grouped in, but be not limited to, the following topics: 1) productivity models and measurement ([8-11]); 2) productivity improvement ([12-15]); 3) factors affecting labor productivity ([16-23]); 4) learning curve theory and application ([24-28]); and 5) productivity analysis for cumulative impact claims ([29-32]). 
In Iraqi construction sector, a few studies concerned with the subject of productivity construction. Al-Taweel and Saeed [33] measured the averages and standard performance times for work and labors productivity in some construction work items through site studying by using work study. Tahar [34] measured the standard productivity for the employers for some construction work items by using the questionnaires styles distributed to different levels of management. The researcher can immobilization the productivity for (600) items for different works items in construction work. Abd-allah [35] studied a group of parameters which affect the application of incentive schemes in the construction companies in Iraq. The effect of these parameters on productivity was studied through the preparation of three questionnaire sets distributed to different levels of management. Al-Zwainy [36] used Back-propagation Feed-forward neural networks for productivity estimation of the finishing works with stone tiles for building project.

In this study, the researcher will be comparing the results of the two different methods to estimate productivity of marble finishing works for floors; these two methods are regression analysis and neural networks. For the subject of estimation construction productivity by neural networks has been completed as an independent research and published in the ARPN Journal of Engineering and Applied Sciences, by the same researcher [37]. In this research will be to predict construction productivity for the same work item using multiple linear regressions and then a comparison between the two methods for the purpose of determining the most accurate method.

\section{Regression Analysis}

Regression analysis is an extremely powerful tool that enables the researcher to learn more about the relationships within the data being studied. There are many texts that describe this technique, and the theory behind its use will not be discussed in detail here. The Simon [38] has found the text by Hogg and Ledolter [39] to be particularly useful.

In this instance multiple linear regression will be used to determine the statistical relationship between a response (e.g., actual productivity) and the explanatory variables (e.g., experience, age). The regression model requires a few assumptions. It is of the form

$$
Y_{i}=\beta_{0}+\beta_{1} X_{1}+\beta_{2} X_{2}+\cdots+\beta_{p} X_{i p}+\varepsilon_{i}
$$

where:

$$
I=1,2, \cdots, n
$$

$Y_{\mathrm{i}}$ is the response that corresponds to the levels of the explanatory variables $X_{1}, X_{2}, \cdots, X_{p}$ at the $i$ th observation.

- $\beta_{0}, \beta_{1}, \cdots, \beta_{p}$ are the coefficients in the linear relationship. For a single factor $(p=1), \beta_{0}$ is the inter- cept, and $\beta_{1}$ is the slope of the straight line defined.

- $\varepsilon_{1}, \varepsilon_{2}, \cdots, \varepsilon_{n}$ are errors that create scatter around the linear relationship at each of the $i=1$ to $n$ observations. The regression model assumes that these errors are mutually independent, normally distributed, and with a zero mean and variance $\sigma^{2}$. It is important to rate that this sometimes difficult to achieve [38].

To make estimates of the coefficients in the regression model, the method of least squares is used for both its mathematical convenience and its ability to provide explicit expressions for these estimates.

\section{Factors Affecting Construction Productivity}

Identification and evaluation of factors affecting labour construction productivity have become a critical issue facing project managers for a long time in order to increase productivity in construction. Understanding critical factors affecting productivity of both positive and negative can be used to prepare a strategy to reduce inefficiencies and to improve the effectiveness of project performance. Knowledge and understanding of the various factors affecting construction labour productivity is needed to determine the focus of the necessary steps in an effort to reduce project cost overrun and project completion delay, thereby increasing productivity and overall project performance. Based on the study and survey, although many researchers have been done and produce the factors that affect productivity, there are still many productivity problems that remain unknown and need to be further investigated even in developed countries [40]. In addition, policies for increasing productivity are not necessarily the same in every country. And the critical factors in developing countries differ from that in developing countries.

The methodology used in this research to determine the factors affecting the productivity of finishing flooring with marble, involves; Literature survey and Preliminary interviews.

The researcher conducted a number of personal interviews with five (60) engineers who have extensive experience in managing construction projects in Iraq. Some of these engineers work as a project manager, estimators, planners and site engineers, and they working with different companies at the Ministry of Construction and Housing Iraqi. And all these engineers with experience not less than twenty years in the field of specialization.

Relying on personal interviews and the literature review, the researcher was able to identify the factors affecting the construction productivity. Ten independent variables were carefully selected and were well defined for each construction project. These independent variables can be classified into two types: objective and subjective variables as shown in Tables $\mathbf{1}$ and 2, respec- 
tively below.

The quantitative (objective) variables that can be measured, depending on the unit of measurement, such as age is measured in years, experience is measured in years and floor height is measured in meters.

The qualitative (subjective) variables can be measured depending on the coding system, for example, the security conditions can be classifies to security and non-security and assigns them the value 1 and 2, respectively. Also the health status for work team which specifies as good, moderate and bad, it assigns them the values of 1 , 2 and 3 , respectively. While the weather condition; sunny (1), rainy (2). The site conditions can be classifies to complex and simple and assigns them the value 1 and 2 , respectively. Where as the scale of 1 and 2 represent near and far, respectively about availability of construction materials.

\section{Data Collection}

Researcher has identified that suitable method of data collection influenced the accuracy of the production rates values. However questionnaire survey is the most commonly data collection method adopted by the researcher to collect information on factors and production Therefore, direct observation method has been selected for collecting the data in this research. Pilot study has been done by selecting ten construction projects in different parts of Iraq. Work sampling approach has been used to measure the production rates at site to calculate duration of activity on daily basis at specific time interval using stop watch. Researcher has been able to get fifteen (15) number of observation from each of ten (10) projects at

Table 1. The objective variables.

\begin{tabular}{ccc}
\hline Objective variables & Description & Units \\
\hline X1 & Age & Year \\
X2 & Experience & Year \\
X3 & Number of the labor & Number \\
X4 & Height of the floor & Length (meter) \\
X5 & Size of the marbles tiles & Area \\
\hline
\end{tabular}

Table 2. The subjective variables.

\begin{tabular}{crc}
\hline Subjective variables & Description & Units \\
\hline X6 & The security conditions & Category \\
X7 & The health status for the work team & Category \\
X8 & Weather conditions & Category \\
X9 & Site condition & Category \\
X10 & Availability of construction materials & Category \\
\hline
\end{tabular}

different intervals. Among ten projects five residential, commercial and educational projects are from Baghdad, four residential projects is from Arbil and one commercial project is from Babylon as shown in Table 3. Therefore total one hundred and fifty (150) number of data samples has been gathered.

\section{Development of Multivariable Linear Regression Model}

Several functions can be used for studying the relationships among the variables of a given data which were stated previously at previous section. Multivariable Linear Regression (MLR) is adopted in the research since the MLR is the most widely used type and using the project characteristics (parameters) in a mathematical model to predict construction productivity.

The Statistical Product and Solutions Services (SPSS) software; Vertion. 19 is used to develop the model, and the results of the statistical analysis are shown in Table 4 and Table 5 below.

The correlation among input variables is tested; the results are shown in Table 4. The results of $r$ (coefficient of correlation) and $r^{2}$ (coefficient of determination) show that there is a high correlation between construction productivity and other input variables. This indicates a good relationship between dependent and independent variables.

Table 3. Construction project visited for measuring labor productivity rates.

\begin{tabular}{cccc}
\hline Project No. & Location & Sample data & Type of project \\
\hline Prj.1 & Baghdad City & 15 & residential project \\
Prj.2 & Baghdad City & 15 & residential projects \\
Prj.3 & Baghdad City & 15 & educational projects \\
Prj.4 & Baghdad City & 15 & educational projects \\
Prj.5 & Baghdad City & 15 & commercial project \\
Prj.6 & Erbil City & 15 & residential projects \\
Prj.7 & Erbil City & 15 & residential projects \\
Prj.8 & Erbil City & 15 & residential projects \\
Prj.9 & Erbil City & 15 & residential projects \\
Prj.10 & Babylon City & 15 & commercial project \\
\hline
\end{tabular}

Table 4. Model Summary.

\begin{tabular}{ccccc} 
Model & $\mathrm{R}$ & \multicolumn{2}{c}{$\mathrm{R}$ square } & Adjusted R square \\
\hline 1 & $0.906^{\mathrm{a}}$ & 0.821 & 0.801 & 2.45965 \\
\hline
\end{tabular}

aPredictors: (Constant), area, material, site, age, security, weather, labour, height, experiences, health. 
Table 5. Uonstandard coefficients of variables.

\begin{tabular}{ccc}
\hline \multirow{2}{*}{ Model } & \multicolumn{2}{c}{ Unstandardized coefficients } \\
\cline { 2 - 3 } (Constant) & 39.233 & B \\
age & 0.038 & 0.044 \\
experiences & -0.056 & 0.052 \\
health status of work team & -8.026 & 1.371 \\
Weather condition & -1.447 & 0.818 \\
Height of the floor & -1.523 & 0.801 \\
No. of labour & -0.560 & 0.552 \\
Security conditions & 0.489 & 1.860 \\
Site condition & 0.822 & 0.577 \\
Material available & -0.066 & 0.674 \\
Size marble & 46.901 & 13.585 \\
\hline
\end{tabular}

The values above indicate that at least one of the model coefficients is nonzero. The model appears to be useful for predicting the construction productivity. This model included all the potential independent variables that have been identified. The model obtained is:

$$
\begin{aligned}
P= & 39.233+0.038 X 1-0.056 \times 2-0.560 X 3 \\
& -1.523 X 4+46.901 X 5+0.489 X 6 \\
& -8.026 \times 7-1.447 X 8+0.822 X 9-0.066 \times 10
\end{aligned}
$$

where:

$P$ : productivity of marble finishing works for floors as output (dependent) variable;

$X 1, X 2, X 3, X 4, X 5, X 6, X 7, X 8, X 9, X 10$ : Input (independent) variables are shown in Tables 1 and 2.

\section{Validation Model}

There are several basic ways of validating a regression model. They are:

1) Statistical test on " $r$ " value.

2) Collection of new data to check the model and its predictive ability for comparison of results with the actual productivity of marble finishing works for floors and the predicted productivity values

\subsection{Statistical Test on “ $R$ ” Value}

The following statistical tests were conducted on " $R$ " (the coefficient of correlation) value for model 1 , where $R^{2}=0.821, N=100$ :

1) Probable Error (P.E.) in " $R$ ” value

$$
\text { P.E. }=0.6745\left[\frac{\left(1-R^{2}\right)}{\sqrt{N}}\right]
$$

P.E. $=0.01207355$ therefore, $R=0.906 \pm 0.01207355$.

According to Gupta [41]; the probable error is regarded as a measure of significance of Karl Person's coefficient of correlation $(R)$, and if the probable error is small (compared with $R$ ), correlation directly exists where $R>0.5$.

Hence, the correlation of the studied productivity equation is existing.

2) Standard Error (S.E.) in " $R$ " value

$$
\text { S.E. }=\left(\frac{1+R^{2}}{\sqrt{N}}\right)
$$

S.E. $=0.1906$.

Hence, the correlation is accepted for $R=0.906$, and 100 observations.

3) Test of significance

Gupta [41]; indicates that the correlation may be accepted when $R>0.22$ (for 100 observations).

Again, the correlation is accepted for $R=0.906$, and 100 observations.

4) A simple method of testing whether " $R$ " differs significantly from "zero"

Taking null hypothesis that there is no correlation between the two variables, provided " $N$ " is large:

$$
\frac{3}{\sqrt{N}}
$$

IF the value arrived at by this test is greater than the observed or computed value of correlation coefficient $\left(R<\frac{3}{\sqrt{N}}\right)$ correlation is not significant [41];

$$
\frac{3}{\sqrt{N}}=\frac{3}{\sqrt{100}}=0.3<0.906
$$

Hence, coefficient of correlation can be taken as significant.

\subsection{Collection of New Data to Check the Model and Its Predictive Ability}

In this research, the second method is employed also. Ten new observations for each concerning variables were collected as shown in Table 6. These observations which were not included in the model calibration procedures were used as independent verification check. While the actual productivity of marble finishing works for floors and the predicted values are presented in Table 7.

Table 7 shows that the predicted productivity (by suggested productivity estimation function) predicts an average difference of $1.291 \%$ of the actual productivity. and the correlation coefficient between them equal to 0.862 . also the analyzed results indicates that the produc- 
Table 6. Number of observations for each variable.

\begin{tabular}{|c|c|c|c|c|c|c|c|c|c|c|}
\hline \multirow{2}{*}{ 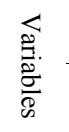 } & \multicolumn{10}{|c|}{ No. observations } \\
\hline & 1 & 2 & 3 & 4 & 5 & 6 & 7 & 8 & 9 & 10 \\
\hline $\mathrm{X} 1$ & 45 & 40 & 40 & 40 & 50 & 50 & 35 & 38 & 45 & 40 \\
\hline $\mathrm{X} 2$ & 20 & 15 & 20 & 20 & 18 & 18 & 15 & 22 & 35 & 35 \\
\hline X3 & 1 & 2 & 2 & 2 & 2 & 1 & 2 & 1 & 1 & 1 \\
\hline $\mathrm{X} 4$ & 1 & 1 & 1 & 2 & 1 & 2 & 1 & 1 & 1 & 1 \\
\hline $\mathrm{X} 5$ & 1 & 3 & 3 & 2 & 2 & 1 & 2 & 1 & 1 & 1 \\
\hline X6 & 4 & 3 & 3 & 3 & 3 & 4 & 3 & 4 & 4 & 3 \\
\hline X7 & 1 & 1 & 2 & 1 & 2 & 1 & 2 & 1 & 1 & 1 \\
\hline X8 & 1 & 1 & 2 & 1 & 2 & 1 & 2 & 1 & 1 & 1 \\
\hline X9 & 1 & 1 & 1 & 1 & 1 & 1 & 1 & 1 & 2 & 1 \\
\hline $\mathrm{X} 10$ & 0.18 & 0.18 & 0.18 & 0.15 & 0.15 & 0.15 & 0.21 & 0.21 & 0.21 & 0.21 \\
\hline
\end{tabular}

Table 7. The actual productivity and the predicted predicated.

\begin{tabular}{cccc}
\hline $\begin{array}{c}\text { No. } \\
\text { observations }\end{array}$ & $\begin{array}{c}\text { Actual } \\
\text { productivity }\end{array}$ & $\begin{array}{c}\text { Predicated } \\
\text { productivity }\end{array}$ & ABS(A-P)/A \\
\hline 1 & 35 & 36.27 & 0.036405 \\
2 & 21 & 25.85 & 0.231056 \\
3 & 21 & 26.88 & 0.280151 \\
4 & 28 & 24.24 & 0.134245 \\
5 & 21 & 27.49 & 0.309102 \\
6 & 31.5 & 33.72 & 0.070544 \\
7 & 28 & 26.6 & 0.049995 \\
8 & 35 & 37.30 & 0.065806 \\
9 & 35 & 36.77 & 0.05072 \\
10 & 35 & 37.21 & 0.063177 \\
\hline
\end{tabular}

tivity of marble finishing works for floors by suggested productivity estimation function are closer to the actual productivity.

\section{Accuracy of the Developed Multivariable Linear Regression Models}

The statistical measures used to measure the performance of the models included [41]:

1) Mean Absolute Percentage Error (MAPE),

$$
\text { MAPE }=\left(\sum_{i=1}^{n} \frac{|A-E|}{A} * 100 \%\right) / n
$$

2) Average Accuracy Percentage (AA\%)

$$
\mathrm{AA} \%=100 \%-\mathrm{MAPE}
$$

3) The Coefficient of Determination $\left(R^{2}\right)$;

4) The Coefficient of Correlation $(R)$;

Table 8 shows a summary of the developed regression models in the study, the results of the comparative study are given in Table 8. The MAPE and Average Accuracy Percentage generated by MLR model were found to be (3.74\%) and (96.3\%) respectively. Therefore, it can be concluded that the MLR model show very good agreement with the actual measurements.

The comparison between the predicated and measured the productivity of marble finishing works for floors is plotted in Figure 1. It is clear from this figure, the ability of multivariable linear regression technique to predict the productivity of marble finishing works for floors for any of data set within the range data used in developing the multivariable linear regression approach.

The coefficient of determination $\left(R^{2}\right)$ is $(82.13 \%)$, as shown in Figure 1, therefore it can be concluded that ANN models show very good agreement with actual measurements.

\section{Comparison of Productivity Modeling between MLR Technique and ANN}

Artificial Neural Networks (ANN) are sophisticated methods that are used to estimation the construction productivity in the construction sector, and the researcher using the results of a previous study prepared by AlZwainy et al. 2012, for the purposes of comparison with the results of this study. The estimation performances of

Table 8. Statistical measures results.

\begin{tabular}{lcccc}
\hline Measures & MAPE $\%$ & AA\% & $R$ & $R^{2}$ \\
\hline Results & 3.74 & 96.3 & 0.906 & 0.821 \\
\hline
\end{tabular}

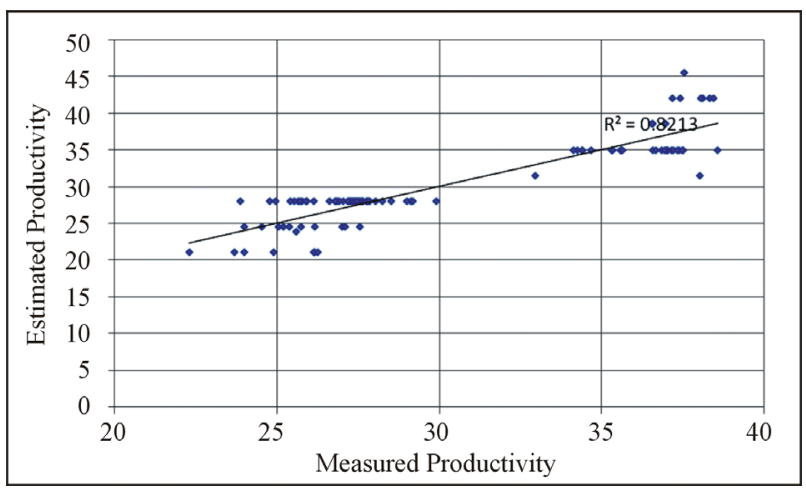

Figure 1. Comparison of predicted and observed productivity. 
the two techniques are compared using four measurements as shown in Table 9. The results can be seen that the MLR technique gives insignificantly better results than the NN technique in almost all comparisons. The findings showed that the two models were able to map the underlying relationship between the independent factors and the construction productivity during and maintained average accuracy percentages of $90.9 \%$ and $96.3 \%$ for neural nets and regression respectively. On the other hand, these results indicate that there is no significant difference in the average accuracy achieved by the two techniques. The high levels of accuracy obtained by the two models can be attributed to the high correlation coefficients between the construction productivity and the effect factors.

\section{Conclusions}

From the results presented in this research, the following conclusions can be made:

1) This study aimed at developing construction productivity estimating model for marble finishing works of floors using multiple regression techniques. The model was developed based on 100 set of data collected in Iraq. Such types of models are very useful, especially in its simplicity and ability to be handled by calculator or a simple computer program.

2) Multivariable Linear Regression (MLR) can be used to examine several variables at once and the interrelationships between them. And MLR has the ability to predict the productivity of marble finishing works for floors with high degree of accuracy with $96.3 \%$ and the coefficients of determination $\mathrm{R}^{2}$ for the developed models equal to 0.8213 . This indicates that the relationship between the independent and independent variables of the developed models is good and the predicted values from a forecast model fit with the real-life data.

3) In this research, ten influential variables used developing construction productivity estimating model. Size marbles have most significant effect on the productivity of marble finishing works for floors equal to 46.901 as an unstandardized coefficients. While the other input variables have moderate impact on the productivity such as health status of work team.

4) This study showed that the technique of Multivari

Table 9. Estimation performances of the MLR and ANN techniques.

\begin{tabular}{ccccc}
\hline \multicolumn{5}{c}{ Productivity of marble finishing works for floors models } \\
\hline Types of model & AA\% & MAPE\% & $R \%$ & $R^{2} \%$ \\
ANN & 90.9 & 9.1 & 89.55 & 80.19 \\
MLR & 96.3 & 3.743 & 90.6 & 82.13 \\
\hline
\end{tabular}

able Linear Regression was more accurate than Neural Networks, because the degree of accuracy reached $96.3 \%$ for Multivariable Linear Regression, while the degree of accuracy reached $96.3 \%$ for Neural Networks.

\section{REFERENCES}

[1] J. Portas and S. AbouRizk, "Neural Network Model for Estimating Construction Productivity," Journal of Construction Engineering and Management, Vol. 123, No. 4, 1997, pp. 399-410. doi:10.1061/(ASCE)0733-9364(1997)123:4(399)

[2] D. Arditi, O. B. Tokdemir and K. Suh, "Effect of Learning-of-Balance Scheduling," International Journal of Project Management, Vol. 19, No. 5, 2001, pp. 265-277. doi:10.1016/S0263-7863(99)00079-4

[3] D. G. Proverbs, G. D. Holt and P. O. Olomolaiye, "A Comparative Evaluation of Planning Engineers' Formwork Productivity Rates in European Construction," Building and Environment, Vol. 33, No. 4, 1998, pp. 181-187. doi:10.1016/S0360-1323(97)00035-8

[4] J. Christian and D. Hachey, "Effects of Delay Times on Production Rates in Construction," Journal of Construction Engineering and Management, Vol. 121, No. 1, 1995, pp. $20-26$. doi:10.1061/(ASCE)0733-9364(1995)121:1(20)

[5] A. Kazaz and S. Ulubeyli, "A Different Approach Toconstruction Labour in Turkey: Comparative Productivity Analysis," Building and Environment, Vol. 39, No. 1, 2004, pp. 93-100. doi:10.1016/j.buildenv.2003.08.004

[6] C. H. Oglesby, H. W. Parker and G. A. Howell, "Productivity Improvement in Construction," McGraw-Hill Book Co., New York, 1989.

[7] R. Sonmez and J. E. Rowings, "Construction Labor Productivity Modeling with Neural Networks," Journal of Construction Engineering and Management, Vol. 124, No. 6, 1998, pp. 498-504. doi:10.1061/(ASCE)0733-9364(1998)124:6(498)

[8] J. C. Kellogg, G. E. Howell and D. C. Taylor, "Hierarchy Model of Construction Productivity," Journal of the Construction Division, Vol. 107, No. 1, 1981, pp. 137-152.

[9] Business Roundtable, "Construction Productivity Measurement," Report No. A-1, Business Roundtable, New York, 1982.

[10] H. R. Thomas and I. Yiakoumis, "Factor Model of Construction Productivity," Journal of Construction Engineering and Management, Vol. 113, No. 4, 1987, pp. 626-639. doi:10.1061/(ASCE)0733-9364(1987)113:4(623)

[11] H. R. Thomas, W. F. Maloney, R. M. W. Horner, G. R. Smith, V. K. Handa and S. R. Sanders, "Modeling Construction Labor Productivity," Journal of Construction Engineering and Management, Vol. 116, No. 4, 1990, pp. 705-726. doi:10.1061/(ASCE)0733-9364(1990)116:4(705)

[12] J. D. Borcherding, "Improving Productivity in Industrial Construction," Journal of the Construction Division, Vol. 102, No. 4, 1976, pp. 599-613. 
[13] J. D. Borcherding, S. J. Sebastian and N. M. Samelson, "Improving Motivation and Productivity on Large Projects," Journal of the Construction Division, Vol. 106, No. 1, 1980, pp. 73-89.

[14] W. F. Maloney, "Productivity Improvement: The Influence of Labor," Journal of Construction Engineering and Management, Vol. 109, No. 3, 1983, pp. 321-334. doi:10.1061/(ASCE)0733-9364(1983)109:3(321)

[15] C. H. Oglesby, H. W. Parker and G. A. Howell, "Productivity Improvement in Construction," McGraw-Hill, Inc., New York, 1989.

[16] R. D. Logcher and W. C. Collins, "Management Impacts on Labor Productivity," Journal of the Construction Division, Vol. 104, No. 4, 1978, pp. 447-461.

[17] H. R. Thomas, V. E. Sanvido and S. R. Sanders, "Impact of Material Management on Productivity-A Case Study," Journal of Construction Engineering and Management, Vol. 115, No. 3, 1989, pp. 370-384. doi:10.1061/(ASCE)0733-9364(1989)115:3(370)

[18] C. W. Ibbs and W. E. Allen, "Quantitative Impacts of Project Change," Source Document 108, Construction Industry Institute, University of Texas at Austin, 1995.

[19] C. W. Ibbs, "Quantitative Impacts of Project Change: Size Issues," Journal of Construction Engineering and Management, Vol. 123, No. 3, 1997, pp. 308-311. doi:10.1061/(ASCE)0733-9364(1997)123:3(308)

[20] A. S. Hanna, J. S. Russell, T. W. Gotzion and E. V. Nordheim, "Impact of Change Orders on Labor Efficiency for Mechanical Construction," Journal of Construction Engineering and Management, Vol. 125, No. 3, 1999, pp. 176-184. doi:10.1061/(ASCE)0733-9364(1999)125:3(176)

[21] H. R. Thomas, D. R. Riley and V. E. Sanvido, "Loss of Labor Productivity Due to Delivery Methods and Weather," Journal of Construction Engineering and Management, Vol. 125, No. 1, 1999, pp. 39-46. doi:10.1061/(ASCE)0733-9364(1999)125:1(39)

[22] W. Ibbs, "Impact of Change's Timing on Labor Productivity," Journal of Construction Engineering and Management, Vol. 131, No. 11, 2005, pp. 1219-1229. doi:10.1061/(ASCE)0733-9364(2005)131:11(1219)

[23] A. S. Hanna, C. K. Chang, J. A. Lackney and K. T. Sullivan, "Impact of Overmanning on Mechanical and Sheet Metal Labor Productivity," Journal of Construction Engineering and Management, Vol. 133, No. 1, 2007, pp. 22-28. doi:10.1061/(ASCE)0733-9364(2007)133:1(22)

[24] H. R. Thomas, C. T. Mathews and J. G. Ward, "Learning Curve Models of Construction Productivity," Journal of Construction Engineering and Management, Vol. 112, No. 2, 1986, pp. 245-258. doi:10.1061/(ASCE)0733-9364(1986)112:2(245)

[25] J. G. Everett and S. Farghal, "Learning Curve Predictors for Construction Field Operations," Journal of Construction Engineering and Management, Vol. 120, No. 3, 1994, pp. 603-616. doi:10.1061/(ASCE)0733-9364(1994)120:3(603)

[26] J. P. Couto and J. C. Teixeira, "Using Linear Model for Learning Curve Effect on Highrise Floor Construction,"
Construction Management \& Economics, Vol. 23, No. 4, 2005, pp. 355-364. doi:10.1080/01446190500040505

[27] A. M. Jarkas, "Critical Investigation into Applicability of the Learning Curve Theory to Rebar Fixing Labor Productivity," Journal of Construction Engineering and Management, Vol. 136, No. 12, 2010, pp. 1279-1288. doi:10.1061/(ASCE)CO.1943-7862.0000236

[28] A. M. Jarkas and M. Horner, "Revisiting the Applicability of Learning Curve Theory to Formwork Labour Productivity," Construction Management \& Economics, Vol. 29, No. 5, 2011, pp. 483-493. doi:10.1080/01446193.2011.562911

[29] H. R. Thomas and I. Zavrski, "Construction Baseline Productivity: Theory and Practice," Journal of Construction Engineering and Management, Vol. 125, No. 5, 1999, pp. 295-303. doi:10.1061/(ASCE)0733-9364(1999)125:5(295)

[30] H. R. Thomas and V. E. Sanvido, "Quantification of Losses Caused by Labor Inefficiencies: Where Is the Elusive Measured Mile?" Construction Law and Business, Vol. 1, No. 3, 2000, pp. 1-14.

[31] W. Ibbs and M. Liu, "Improved Measured Mile Analysis Technique," Journal of Construction Engineering and Management, Vol. 131, No. 12, 2005, pp. 1249-1256. doi:10.1061/(ASCE)0733-9364(2005)131:12(1249)

[32] L. D. Nguyen and W. Ibbs, "Case Law and Variations in Cumulative Impact Productivity Claims," Journal of Construction Engineering and Management, Vol. 136, No. 8, 2010, pp. 826-833. doi:10.1061/(ASCE)CO.1943-7862.0000193

[33] N. Al-Taweel and M. A. Saeed, "Measuring Standard Times for Labors Productivity for a Number of Different Work Items," Journal in Engineering and Technology, Vol. 10, No. 2, 2005, 1991, pp. 249-256.

[34] A. J. Tahar, "Studying Labour Productivity for Some Working Items in Construction Projects," Msc. Thesis, University of Technology, Iraq, 1995.

[35] A. Abd-allah, "Effect of Wages and Incentives on Labours Productivity in Construction Sector in Iraq," Master Thesis, University of Technology, Iraq, 1999.

[36] F. M. S. Al-Zwainy, "The Use of Artificial Neural Networks for Productivity Estimation of finishing Stone Works for Building Projects," Journal of Engineering and Development, Vol. 16, No. 2, 2012, pp. 42-60. http://www.iasj.net/iasj?func=fulltext\&aId $=68252$

[37] F. M. S. Al-Zwainy, A. R. Hatem and F. I. Huda, "Using Artificial Neural Network for Finishing Works for Floors with Marble," ARPN Journal of Engineering and Applied Sciences, Vol. 7, No. 6, 2012, pp. 714-722.

http://www.arpnjournals.com/jeas/research_papers/rp_20 12/jeas_0612_714.pdf

[38] R. V. Hogg and J. Ledolter, "Applied Statistics for Engineers and Physical Scientists," 2nd Edition, Macmillan, New York, 1992.

[39] S. D. Smith, "Earthmoving Productivity Using Linear Regression Techniques," Journal of Construction Engineering and Management, Vol. 125, No. 3, 1999, pp. 133-141. doi:10.1061/(ASCE)0733-9364(1999)125:3(133) 
[40] A. Makulsawatudom and M. Emsley, "Critical Factors Influencing Construction Productivity in Thailand," Journal of KMITNB, Vol. 14, No. 3, 2004, pp. 1-6.

[41] B. N. Gupta, "An Introduction to Modern Statistics,"
Indian Institution of Public Administration, New Delhi, 1973. 